\title{
Ethical Questions in the Treatment of Spinal Cord Injured Patients *
}

\author{
Abraham Ohry, M.D. \\ Sir Ludwig Guttmann Spinal Cord Injury Unit, Rehabilitation Center, Sheba \\ Medical Center, Tel Hashomer, 52621, Israel
}

\begin{abstract}
Summary
Modern medicine has greatly benefitted spinal cord injured patients. The daily process of their rehabilitation, however, creates serious ethical problems, which the clinician attempts to solve using a humanistic, multidisciplinary and interdisciplinary approach. We present some of those conflicts, especially those caused by the survival of totally dependent patients and those related to our communication with the patient and his family.
\end{abstract}

\section{Introduction}

Since the great pioneering works of Guttmann, Munro, Rusk, and others, the quality of life of spinal cord injured patients (S.C.I.P.), their life span and their reintegration into society have improved dramatically. Today, those who care for S.C.I.P. are confronted with various ethical problems as a result of the advances in modern medicine. Sir Ludwig Guttmann taught us the principles of total S.C.I.P. rehabilitation, stressing a multidisciplinary and interdisciplinary approach (Guttmann 1976, 1977, 1978). We face and try to solve these ethical questions within this perspective.

One of the earliest problems to appear is whether or not to operate on the acute injured patient: is there any need for 'decompressive' laminectomy, or is conservative treatment preferable? (The first academic dispute on this subject took place in 1824 between Sir Charles Bell and Sir Astley Cooper). Another primary difficulty is caused by the permanent, world-wide lack of rehabilitation beds. Who should be admitted, who has rehabilitative potential, and who does not? We encounter this dilemma because we believe that society should provide for the needs of its disabled, and that 'medicine is a broad discipline, a helping profession, which has a constantly growing body of knowledge to call upon ... biomedical science is but the centrepiece of an amalgam of concepts useful in the care of the patient. The method through which this amalgam is applied is the doctor-patient relationship, a human inter-activity which has amoeboid rather than sharp borders, drawing into its corpus those things that most logically fulfil the patient's needs. Medicine deals with mind/body, disease/

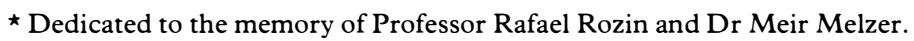


illness and person/society as a continuum.... It is on the strength of its inclusive character that medicine can prevent disability, relieve pain, cure disease, care for illness and promote life ...' (Perkoff, 1985).

Following spinal injury, life becomes very different: much more sedentary, with paradoxes such as paralysed limb movement (spasticity), and painful anaesthetic regions (phantom pain). Since there is a constancy of the 'internal environment', as Claude Bernard described it, the entire organism slowly changes, both physiologically and psychologically, in order to maintain this constancy within the new situation. The homeostatic mechanisms help body and mind to adapt. René Dubos has said (1968) that 'man has the privilege and responsibility of shaping his self and his future'. But when we sometimes use behavioural methods as an instrument of rehabilitation, we face another conflict: how far may we go in our attempts to change or correct the patient's body image or frame of mind? How much can we interfere with his own ego defence mechanisms? (Trieschman, 1980).

The limits of medicine are expanding, confronting us with new challenges: acute patients are resuscitated, sometimes operated on, ventilated, then rehabilitated. More patients with high cervical injuries survive thanks to artificial respiration and to phrenic nerve pacing. They become totally dependent on man and machine, confined to a powered wheelchair, needing permanent artificial respiration and a complicated, computerised environmental control system. The paraplegic suddenly finds himself thrown into a whole new mechanical world made of beds, wheelchairs, devices, respirators, etc., which will always dictate to him his interaction with his surroundings (Ohry, 1986). No wonder then that many such patients, in spite of all our efforts, feel 'different', 'strange', or alienated. The quality of their life is very problematic. Their condition robs them of almost all their freedom to choose, to decide, and to implement those decisions by themselves. Yet they have a will of their own, just like any other human being. This situation creates severe conflicts. If a paraplegic chooses not to live this kind of life, being unable to carry out his decision by himself he may ask his doctor to help him die. Thus the physician will be torn between his understanding for his patient's wish and his duty to preserve life. This type of conflict also exists in other fields of medicine, but here it is particularly acute.

The relationship between patient and physician is an important element of clinical practice in all medical fields. In rehabilitation, however, this aspect becomes particularly significant, and thus problematic, because the physician is almost always the primary source of critical information for the S.C.I.P. A successful encounter between the patient and the rehabilitation staff is a crucial factor for a satisfactory outcome of the entire rehabilitation process (Brull, 1981, 1985). We are usually asked at an early stage whether there is any chance of recovery. The manner in which we break the news to the patient and to his family may make a difference, regardless of the eventual outcome of the case. The 'how', 'when', and 'to whom' the bad news should be delivered is the task of the clever, tactful physician (this may remind us of the 'right moment' which Hippocrates taught us). We are constantly exposed to new 'revolutionary' or 'miraculous' cures of spinal injuries. It is our duty to explain that there is no cure, but only care, to encourage our patients, promote motivation, often despite depression or a lack of co-operation. 
Since we aim to bring the handicapped back into the mainstream of society, we must attempt to 'normalise' them. This is a risk process involving the elimination of the artificial, 'sanitised' life in hospital, replacing it by the possibility of failure but also of greater rewards (Park, 1975). Another issue confronting the physician often arises when these patients demand compensation from various institutions, such as insurance companies. The rehabilitation specialist is requested to testify to their needs. He may find himself in a dilemma between the patient's genuine needs and those of the lawyer.

Guttmann wrote in 1976: 'We have all been entrusted with talents in life, and when the challenge comes to some of us in the nature of some physical disaster, we employ these talents according to our individual personalities, conditioned by environmental and hereditary factors ... (the S.C.I.P.) are rewarded for their endeavours by regaining their self-confidence and self-respect, and in spite of their remaining disability, become useful and respected members of society.' The goals of rehabilitation are clear, but the ethical guidelines to achieve them are not, a fact of which the clinician in his daily work is well aware.

\section{Acknowledgement}

My thanks to my wife Karin, without her help and encouragement this work could not have been completed.

\section{References}

BELl C 1824 Lectures on the spine, in 'Observations on injuries of the spine and the thigh bone', London, Thomas Tegg, pp. 2-33

BRULl F 1981 Keywords in psychiatry. The Family Physician (Heb) 10:150-155

BRULL F 1985 On the issue of will. Israel fournal of Psychiatry Related Sciences 22:7-11

Dubos R 1968 So human and animal. Scribner, New York, p. 106

GuttMAnN L 1976 The ultimate integrities of the spinal man. Chapter 41 in Spinal Cord Injuries, Blackwell, 2nd ed. Oxford p. 676

GUTTMANN L 1977 On health deviation and rehabilitation in spinal paraplegics and tetraplegia Community Health 8:186-208

GUTTMANN L 1977-8 Total responsibility of the surgeon in the treatment of traumatic spinal paraplegics and tetraplegics. Paraplegia 15:285-292

OHRY A 1986 The quadriplegic patient and his environment: the human factor. Harefuah (in press)

PARK LD 1975 Barriers against normality for the handicapped adult in the United States. Rehabilitation Literature 36:108-111

PERKOFF GT 1985 The boundaries of medicine. Fournal of Chronic Diseases 38:271-278

TRIESCHMANN RB 1980 Adjustment to spinal cord injury; an overview, Chapter 9 in Spinal cord injury: psychological, social and vocational adjustment. Pergamon Press, New York, p. 178 